$\$$ Research Square

\title{
Foliar-applied Silicon and its Nanoparticles Stimulates Physio- chemical Changes to Improve Growth, Yield and Active Constituents of Coriander (Coriandrum Sativum L.) Essential oil Under Different Irrigation Regimes
}

\author{
Minoo Afshari \\ Islamic Azad University Shahre Rey Branch \\ Alireza Pazoki ( Pazoki_agri@yahoo.com ) \\ Islamic Azad University \\ Omid Sadeghipour \\ Islamic Azad University Shahre Rey Branch
}

\section{Original Research}

Keywords: Silicon, Drought stress, Essential oil, Nanotechnology, Phenolic content

Posted Date: February 10th, 2021

DOI: https://doi.org/10.21203/rs.3.rs-176146/v1

License: (c) (i) This work is licensed under a Creative Commons Attribution 4.0 International License. Read Full License

Version of Record: A version of this preprint was published at Silicon on April 15th, 2021. See the published version at https://doi.org/10.1007/s12633-021-01101-8. 


\section{Abstract}

Purpose Silicon (Si) plays beneficial role in alleviating biotic and abiotic stresses but comparative investigations with $\mathrm{Si}$ nanoparticles (Si-NPs) under water restriction on medicinal plants is not recognized. The aim of this study was to observe the Si and Si-NPs effects on growth, physio-chemical attributes, and essential oil (EO) profile in aerial parts of coriander (coriandrum sativum L.) under water stress.

Methods A split-plot experiment was conducted with irrigation regimes (irrigation after 60, 90, and $120 \mathrm{~mm}$ evaporation from Class A pan) in the main plots and foliar application of $\mathrm{Si}$ (in the form of $\mathrm{Na}_{2} \mathrm{SiO}_{3}$ ) and Si-NPs in the subplots during 2019 and 2020.

Results The results represented drought particularly severe stress decreased biological yield and relative water content (RWC) but increased total soluble sugar (TSS). Both Si and Si-NPs improved plant growth and yield through improved RWC, TSS, total phenolic content (TPC) and total flavonoid content (TFC). Moderate drought stress with Si-NPs was highly effective on TPC, TFC, EO percentage and yield. The main EO constitutes were n-Decanal (20.8-27.6\%), 2E-Dodecanal (13.3-16.7\%), 2E-Decanal (13.918.7\%), 2E-Tridecen-1-al (7.3-10.5\%), Dodecanal (7.2-10.6\%), and n-Nonane (4.3-8.7\%). Heat map analysis (HMA) showed foliar application of $\mathrm{Si}$ and Si-NPs were significantly distinguished from control treatment, which was mainly explained by EO yield and TFC attributes.

Conclusion Foliar-applied Si-NPs was the rapidly and highly effective practice to reach the optimum antioxidant capacity and EO yield of coriander plants when experience moderate drought stress.

\section{Introduction}

Drought, as a main abiotic stress, affects physiological and biochemical processes of plants, especially the synthesis and accumulation of secondary metabolites [1]. Under deficit of water supply, chemical signals are transmitted from the roots to the leaf through xylem pathways, in which plants stimulate physiological changes such as stomatal closure, photosynthesis reduction, and enhancement of the antioxidant potential through biochemical pathways like antioxidant enzymes and phenolic content [2]. Secondary metabolites are the principal active compounds in medicinal plants, which affected by drought stress [3]. Therefore, water deficit stress has a greater impact on medicinal plants. The changes in essential oil (EO) yield and composition, phenol and flavonoid contents are the main biochemical response of medicinal plants under drought stress [3].

Silicon (Si) is the principal element on the earth crust. It is considered as the second abundant element in earth crust after oxygen [4]. The positive effect of $\mathrm{Si}$ on plant growth and development under biotic and abiotic stress conditions have been well documented [1, 5]. Si stimulates plant growth through improving nutrients uptake, water content, and the resistance to pathogens and diseases [5]. Recently, the nanotechnology in agriculture sector has been highlighted to cope with environmental disorders. Si nanoparticles (Si-NPs) promotes physiological and biochemical processes to increases plant growth and development under stress conditions [6, 7]. Si-NPs are able to remediate the different stresses especially scavenging the reactive oxygen species (ROS) produced under drought and salinity stresses [8]. Plants have different responses to NPs based on the the size, shape, method of application, and physicochemical properties of the NPs [8].

Coriander (Coriandrum sativum L.) is a medicinal annual Apiaceae specie which widely used because of its high nutritional and medicinal values [9]. Coriander is native to the European-Mediterranean area and was cultivated in China in the 1st century BC. Recently, it has been widely cultivated as a valuable herb all over the world [10]. Fresh aerial part of coriander is usually used as food seasoning. Furthermore, it has various medicinal uses such as treatment of disorders in skin inflammation, digestive, respiratory and urinary systems $[10,11]$.

In recent years, nanotechnology has emerged as a prominent tool for enhancing agricultural productivity. The importance of nanofertilizers is due to their rapid and complete absorption by plants $[8,12]$. The positive effects of foliar application with Si-NPs on plant growth and development under heavy metal [5, 7, 13, 14], UV radiation [15], salinity [16], and drought [4]. However, little is known about involvement of Si and its nanoparticles (Si-NPs) in the regulation of drought effects in plants. Therefore, the aims of present study were (1) to investigate the effect of Si and Si-NPs on biological yield, water and sugar content, and antioxidant capacity (phenol and flavonoid content) of coriander plants, (2) to assess the effect of Si and Si-NPs on EO yield and composition 
of coriander under well-watered and water stress conditions, (3) to determine whether Si or Si-NPs are more effective in alleviating drought stress in coriander, and (4) to explain possible mechanisms by which Si and Si-NPs alleviates drought stress in coriander plants. These results provide an effective practice with $\mathrm{Si}$ and Si-NPs to cope the drought stress on coriander plants in order to reach the optimum EO quality and quantity.

\section{Material And Methods}

\subsection{Experimental site and plant materials}

The field experiment was conducted at the research farm of Islamic

Azad University, Shahre rey Branch, Tehran, Iran (1070 m asl, 35 36 $\left.36^{\prime} 44^{\prime \prime} \mathrm{N}, 5^{\circ} 26^{\prime} 30^{\prime \prime} \mathrm{E}\right)$ in 2019 and 2020. Table 1 shows the soil properties used in the study. The mean annual temperature of first and second years were 16.7 and $16.9^{\circ} \mathrm{C}$, respectively. The total annual precipitation was $216 \mathrm{~mm}$ in the first year and $214 \mathrm{~mm}$ in the second year.

Table 1

Soil analysis of experimental field

\begin{tabular}{|c|c|c|c|c|c|c|c|c|c|c|c|c|}
\hline $\begin{array}{l}\text { Depth } \\
\text { (cm) }\end{array}$ & $\mathrm{pH}$ & $\begin{array}{l}\text { EC } \\
\text { (ds.m- } \\
\left.{ }^{1}\right)\end{array}$ & $\begin{array}{l}\mathrm{Na} \\
\text { (meq. } \text { I }^{-} \\
{ }^{1} \text { ) }\end{array}$ & $\begin{array}{l}\text { P } \\
\text { (mg.kg- } \\
\left.{ }^{1}\right)\end{array}$ & $\begin{array}{l}\text { Organic } \\
\text { carbon } \\
(\%)\end{array}$ & $\begin{array}{l}\mathrm{K} \\
\left(\mathrm{mg} \cdot \mathrm{kg}^{-}\right. \\
\left.{ }^{1}\right)\end{array}$ & $\begin{array}{l}\mathrm{NH}_{4} \\
\text { (mg.kg- } \\
\left.{ }^{1}\right)\end{array}$ & $\begin{array}{l}\mathrm{NO}_{3} \\
\text { (mg.kg- } \\
\text { 1) }\end{array}$ & $\begin{array}{l}\text { Clay } \\
(\%)\end{array}$ & $\begin{array}{l}\text { Silt } \\
\text { (\%) }\end{array}$ & $\begin{array}{l}\text { Sand } \\
(\%)\end{array}$ & $\begin{array}{l}\text { Soil } \\
\text { Texture }\end{array}$ \\
\hline $0-30$ & 7.84 & 1.03 & 6.36 & 10.46 & 1.03 & 598.8 & 5.95 & 14.63 & 31 & 49 & 20 & $\begin{array}{l}\text { Clay } \\
\text { Loam }\end{array}$ \\
\hline $0-30$ & 7.82 & 1.11 & 6.75 & 9.57 & 0.97 & 603.5 & 6.04 & 14.57 & 30 & 49 & 21 & \\
\hline
\end{tabular}

The seeds of coriander were purchased from Pakan Bazr-e-Esfahan Company (Esfahan, Iran), and sown at 19 and 20 April. The area of each plot was $6 \mathrm{~m}^{2}$. The distance between two lines and between two plants on lines was $30 \mathrm{~cm}$ and $20 \mathrm{~cm}$, respectively. The distance between plots was $1 \mathrm{~m}$.

\subsection{Experimental design and treatments}

The split plot experiment was carried out in a randomized complete block design (RCBD) with three replications in 2019 and 2020. Irrigation regimes as main plot were applied in three levels based on evaporation from Class A pan as irrigation after 60, 90, and $120 \mathrm{~mm}$ evaporation from Class A pan. The Si-NPs were purchased from Nano Pasargad Novin company, Tehran, Iran. The Si-NPs included the purity of $99 \%$, particle size of $20-35 \mathrm{~nm}$, and active level of $461 \mathrm{~g} \mathrm{~m}^{-2}$. To homogenize and separate the particles, the

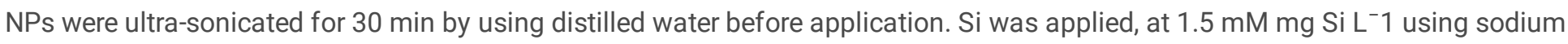
silicate $\left(\mathrm{Na}_{2} \mathrm{SiO}_{3}\right)$ (sodium met silicate powder extra pure $>98.0 \%$; Sigma-Aldrich) as a source. Seed were cultivated in 19 and 20 April by hand. Weeds were controlled manually during the growing season. The drought was applied after emerging 4 leaf, and during the growth period, plants were foliar-applied with a solution containing either without or with $1.5 \mathrm{mM}$ of Si and Si-NPs for three times (both side of leaves) at an interval of 15 days. At harvesting stage (4 months after sowing the seeds), the plants were divided in three groups of fresh, dry, and frozen samples. The frozen samples were kept at $-80^{\circ} \mathrm{C}$ using liquid nitrogen to biochemical assays.

\subsection{Biological yield (BY)}

To measure BY, plants were cut from the bottom of stem, and they immediately were transferred in the envelopes and dried at $40^{\circ}$ $\mathrm{C}$ in the dark condition till got a constant weight [17

\subsection{Relative water content (RWC) measurement}

The RWC of leaves was calculated as a percentage according to the method of Dhopte and Manuel [18] as follows: 


$$
\mathrm{RWC}=\frac{(\mathrm{FW}-\mathrm{DW})}{(\mathrm{SW}-\mathrm{DW})} \times 100
$$

Where, FW is fresh weight, SW is leaf weight after soaking for 24 hours at room temperature and DW is leaf dry weight after drying for $24 \mathrm{~h}$ at $75^{\circ} \mathrm{C}$.

\subsection{Determination of total soluble sugar (TSS)}

To measure the TSS, $95 \%$ and $70 \%$ ethanol was used. $0.5 \mathrm{~g}$ of frozen petals was crush with liquid nitrogen and grind with $5 \mathrm{ml}$ of $95 \%$ ethanol to release sugar, then $5 \mathrm{ml}$ of $70 \%$ ethanol was added in two times and centrifuged at $3500 \mathrm{rpm}$ for $10 \mathrm{~min}$ and kept in the refrigerator for one week. After that, $0.1 \mathrm{ml}$ of the stored stock was mixed with $3 \mathrm{ml}$ antron (150 mg antron and $100 \mathrm{ml} 72 \%$ sulfuric acid). The solution was placed in the boiling water bath at $90^{\circ} \mathrm{C}$ for $10 \mathrm{~min}$. The absorbance was measured at $625 \mathrm{~nm}$ using a UV-Vis spectrophotometer (Shimadzu, Tokyo, Japan) [19].

\subsection{Determination of total phenolic content (TPC)}

Folin-Ciocalteu reagent was selected to measure TPC spectrophotometrically [20]. $100 \mu \mathrm{l}$ of the MeOH solution of the precisely measured weight of investigated plant $1-10\left(2.54,2.58,2.25,4.03,4.80,2.13,4.62,1.47,1.58,15.05 \mathrm{mg} \mathrm{mL}^{-1}\right.$ respectively) were mixed with $0.75 \mathrm{~mL}$ of Folin-Ciocalteu reagent and allowed to stay at $22^{\circ} \mathrm{C}$ for $5 \mathrm{~min}$. The mixture was supplied with $0.75 \mathrm{ml}$ of $\mathrm{NaHCO}_{3}$. Absorbance was measured at $725 \mathrm{~nm}$ by UV-VIS spectrophotometer (Varian Cary 50) after 90 min at $22{ }^{\circ} \mathrm{C}$. Standard curve was calibrated by Gallic acid $\left(0-100 \mathrm{mg} \mathrm{ml}^{-1} ; r>0.99\right)$. The results were represented as $\mathrm{mg}$ Gallic acid (GA) $\mathrm{g}^{-1}$ Dry weight.

\subsection{Determination of total flavonoid content (TFC)}

The flavonoid levels were measured by aluminum chloride colorimetric method [21]. Briefly $0.5 \mathrm{ml}$ of extract solution with $1.5 \mathrm{ml}$ of $95 \%$ ethanol, $0.1 \mathrm{ml}$ of aluminum chloride $10 \%, 0.1 \mathrm{ml}$ of $1 \mathrm{M}$ potassium acetate were mixed with $2.8 \mathrm{ml}$ of distilled water. The mixture vortexed for $10 \mathrm{~s}$ and left to stand at $25^{\circ} \mathrm{C}$ for $30 \mathrm{~min}$. The absorbance of the mixture was read at $415 \mathrm{~nm}$. Quercetin concentrations ( 0 to $1200 \mathrm{\mu g} \mathrm{ml}^{-1}$ ) were prepared and linear fit was used for calibration of the standard curve.

\subsection{EO content}

EO content of flowering branches was quantified using the method described by the European Pharmacopoeia for oil production [22]. Briefly, $100 \mathrm{~g}$ of dried aboveground plant parts were subjected to hydro-distillation for $3 \mathrm{~h}$ using a Clevenger-type apparatus.

\subsection{Gas chromatography (GC) analysis}

Thermo-UFM ultrafast gas chromatograph equipment with a ph- 5 fused silica column ( $10 \mathrm{~m}$ length $\times 0.1 \mathrm{~mm}$ id., film thickness 0.4 $\mu \mathrm{m}$ ) was used to anlyze EOs. Oven temperature was maintained at $60^{\circ} \mathrm{C}$ for $5 \mathrm{~min}$ and then programmed to $285^{\circ} \mathrm{C}$ at a rate of 5 ${ }^{\circ} \mathrm{C}$ min $^{-1}$; flame ionization detector (FID) and injector temperature were $290^{\circ} \mathrm{C}$ and $280^{\circ} \mathrm{C}$, respectively; helium was applied as carrier gas with an inlet pressure of $0.5 \mathrm{~kg} \mathrm{~cm}^{-2}$.

\subsection{Gas chromatography-mass spectrometry (GC-MS)}

GC-MS analyses were accomplished by Varian 3400 GC-MS system equipment with AOC-5000 auto injector and DB-5 fused silica capillary column $(30 \mathrm{~m} \times 0.25 \mathrm{~mm}$ i.d.; film thicknesses $0.25 \mu \mathrm{m})$. Temperature was programmed from $60^{\circ} \mathrm{C}$ to $250^{\circ} \mathrm{C}$ with $3^{\circ} \mathrm{C}$ $\min ^{-1}$; Injector and interface temperature were $260^{\circ} \mathrm{C}$ and $270^{\circ} \mathrm{C}$, respectively; acquisition mass range of $40-340$ amu; ionization voltage of $70 \mathrm{eV}$; the carrier gas was helium at a velocity of $45 \mathrm{~cm} \mathrm{sec}^{-1}$.

\subsection{Component identification}

Homologous series of $n$-alkanes $\left(C_{7}-C_{25}\right)$ determined the retention index for all volatile constituents. According to Adams, the components of oil were identified by matching their retention indices (RI) and mass spectra. EO components were identified by GC/MS spectroscopy [23]. 


\subsection{Data analysis}

The SAS software package for Windows (SAS, version 9.3, SAS Institute, Cary, NC) was used for data analysis. The mean values were compared with Duncan's multiple range tests. The data were statistically analysed at $5 \%$ probability level $(P \leq 0.05)$.

\section{Results And Discussion}

\subsection{Biological yield (BY)}

Figure 1 shows the variation of BY under different irrigation regimes and Si application. The BY decreased by progressing the drought stress but both $\mathrm{Si}$ and Si-NPs increased it $(P \leq 0.05)$. The highest BY was reported in Si-NPs treated plants under wellwater conditions to be $7120 \mathrm{~kg} \mathrm{ha}^{-1}$. The significant reduction of BY was observed in the plants experiencing severe drought stress. Under non-Si application, a 37\% decline of BY was observed under severe water stress compared to well-watered conditions. Thus, both Si and Si-NPs alleviate the adverse effects of drought stress on BY.

Growth (biomass) is a primary process to be changed by water shortage [24]. We observed a decline of growth under moderate and severe stresses. It shows that even at decreased soil water availability, coriander plants are able to grow but in the slow rate. These findings agree with those obtained by Achten et al. [25] (2010) on Jatropha curcas and Sarker and Oba [24] on Amaranthus tricolor, who reported plants are able to grow under deficit water stress but at the slower rate than fully irrigated condition. The decline of BY with progressing drought could be attributed to inhibition of cell elongation and expansion, reduced turgor pressure, use of the energy to conserve cell turgor, which results in reduction of photo-assimilation and metabolites required for cell division [24]. However, both Si and Si-NPs improved the BY at well-watered and water-stressed conditions. Bukhari et al. [1] represented the higher effective role of Si under water stress condition compared to well-watered situation, which it suggests the principal role of Si in plant growth and development at water deficit conditions. Compared to Si, Si-NPs was significant more effective, which is related to the higher availability of Si-NPs with coriander plants than Si. Similar results for the better effect of Si-NPs compared to Si were reported on wheat seedling under UV-B stress [15]. The similar enhancement in biomass of Si-NPs-treated plants was reported in various studies $[5,7,26]$. The Si-NPs may improve the nutrients uptake by plants, which results in higher biomass. In this regard, Si-NPs increases the uptake of Mg, P, K and S contents in stressed plants [26,27]. Moreover, plant biomass may be remarkably improved by Si-NPs which might be due to its placement in the leaf bundle that affect the structure of chloroplasts and leaf yield at the unit level and therefore increase the plant's ability to use light [5].

\subsection{Relative water content (RWC) and total soluble sugar (TSS)}

Although RWC decreased with advancing the water stress, different applications of Si improved the RWC $(P \leq 0.05)$. It differed from $55.6 \%$ in severe-stressed plants with non-Si application to $81.3 \%$ in well-watered plants and Si-NPs treatment (Fig. 2a). Unlike RWC, TSS increased by advancing the rate of drought stress and with Si application. The greatest TSS was obtained in severe stress plants with foliar application of Si-NPs. However, the plants experiencing no drought stress (control) in the absence of Si and Si-NPs had the lowest TSS (Fig. 2b).

The reduction of RWC and enhancement of TSS were the strategy of coriander to cope the stressed conditions. RWC is a useful variable to assesses the physiological water status of plants, which can be used as an important index for determining the tolerant and sensitive plants under stressful environments [24]. Reduced RWC was observed under moderate and severe stresses (Fig. 2, a). The decreases of turgor pressure, water uptake limitation in available water, and prohibition of water uptake by roots lead to reduced RWC in the leaves. Plants exposed to stressed conditions reduce the RWC to reduce the secondary biochemical processes and to maintain the energy on their survival. Moreover, TSS is the highly sensitive variable to environmental stresses [28]. Increased TSS under drought stress has been demonstrated in several studies [29, 30]. In contrast, a few studies have shown that drought significantly decreases the TSS in the whole plant [29]. In this two-year study, moderate and severe drought stresses enhanced sugar accumulation in leaves of coriander plants. Soluble sugar plays the vital role an osmoprotectant, regulating osmotic adjustment, scavenging toxic reactive oxygen species (ROS), and providing membrane protection, and under biotic and abiotic stresses [30]. The accumulation of TSS is an effective strategy of plants to maintain RWC and membrane stability of cells under water stress conditions [30]. 


\subsection{Total phenolic content (TPC) and total flavonoid content (TFC)}

Figure 3 shows the response of TPC and TFC to Si application under different irrigation regimes. The TPC increased under moderate drought stress and also it was improved with $\mathrm{S}$ application. The plants experiencing severe stress condition showed the lowest TPC. This biochemical trait was obtained in a range of $32.62-41.91 \mathrm{mg} \mathrm{GA} \mathrm{g}^{-1} \mathrm{DW}$ in which the highest amount was observed in moderate water stress with Si-NPs spraying. TFC showed the variation under irrigation regimes and Si application. The highest TFC was found in well-watered plants with Si-NPs. The reaction of plants to TFC was different amog the treatments. In non-Si treatments, moderate drought stress increased TPC by $19 \%$ compared to well-watered condition. Generally, the optimum TPC and TFC were reported under moderate stress conditions with foliar application of Si-NPs.

Phenolic compound is an eminent antioxidant factor for protecting the plants from dangerous radicals such as ROS. We found the higher TPC and TFC under moderate water stress and with Si and its nanoparticles, but it decreased in plants experiencing the severe drought (Fig. 3). Similar to our results, Gharibi et al. [31] and Krol et al. [32] showed the increased TPC and TFC under moderate drought but they remained unchanged under severe stress conditions. Therefore, it can be concluded that severe drought stress might inhibit the synthesis of TPC and TFC [32]. Plants use different mechanisms to distribute flavonoids among subcellular compartments [31]. The augmentation of TPC and TFC under high limited water is related to accumulation of soluble carbohydrates in plant cells because of reduced transportation of TSS under drought stress [33]. Phenolics and flavonoids are produced by shikimic acid or phenyl propanoid pathways, and as hydroxyl groups can donate hydrogen and react with ROS in the termination reaction, which ultimately breaks the cycle of producing new radicals. The shikimic acid pathway converti simple carbohydrate precursors into aromatic amino acids [31]. Si and particularly its nanoparticles improved the TPC and TFC. Si and SiNPs due to their role in improving the production of secondary metabolisms such as TPC and TFC can protect the stressful plants from the ROS. The positive role of Si-NPs on polyphenols has been observed on coriander plants grown in lead (Pb)-spiked soil [5].

\subsection{Essential oil (EO) percentage and yield}

Moderate water stress conditions and foliar application of Si-NPs led to higher EO percentage than other experimental treatments. At non-foliar applied plants, moderate water stress improved EO content by $70 \%$ compared to well-watered plants. Under severe drought, Si-NPs and Si increased EO content by $29 \%$ and $22 \%$ compared to non-foliar application (Fig. $4 a$ ). EO yield in moderate drought stress was significantly higher compared to other irrigation regimes. Although, there was no significant difference between Si and Si-NPs in EO yield of coriander plants, these amendments led to increased EO yield (Fig. 4b).

The slight drought stress was effective to reach the optimum EO percentage and yield of aerial parts of coriander. However, the adverse impact of severe drought stress on EO yield of coriander was addressed. Since EO yield is calculated by dry matter and EO percentage, the reduction of shoot biomass and EO percentage results in reduced EO yield [34]. Si and Si-NPs subsided the undesirable effects of severe drought stress and promoted EO yield (Fig. 4). Environmental stresses are important in EO production $[35,36]$. Our results revealed that moderate drought stress along with Si and SO-NPs enhanced EO yield, which confirmed the previous investigations with drought $[37,38]$ or Si application [36]. The enhanced EO amount under slight drought stress may be attributed to the decline in leaf surface and enhancement of oil gland number and density [39]. The abiotic stresses may affect EO production through changing the pathways of secondary metabolites production and their distribution [36]. This study demonstrated the improvement of EO yield by Si and Si-NPs application. Si plays an important role in elicitor-accelerated secondary metabolite production by inducing several transcriptional modifications [40]. Si may increase EO yield via improvement of cell development, ion uptake, and leaf oil gland density and size [41]. Si can enhance the EO production via its different uses such as Si or its nanoparticles. The improvement of EO yield under Si treatment in this work are in agreement with those reported on rosemary [42], geranium [34], and sweet basil [40]. Si and its nanoparticles increased EO production, and probably served as an effective stimulant to increase the production of secondary metabolites [43].

\subsection{Essential oil composition}

The GC/MS analysis showed 22 compounds in EO of coriander (Tables 2 and 3). The main EO constitutes were n-Decanal, 2EDodecanal, 2E-Decanal, 2E-Tridecen-1-al, Dodecanal, and n-Nonane in both 2019 and 2020. N-decanal as a main compound was affected by foliar application of Si-NPs. It differed from $20.80 \%$ at severe water stress and Si to $27.60 \%$ under well-watered conditions and foliar application of Si-NPs. 2E-Decanal (13.30-16.70\%) showed no remarkable variation under irrigation regimes

Page 6/14 
and Si foliar application. Unlike N-decanal, Si and it nanoparticles decreased 2E-Dodecanal in which it ranged from 13.9\% in plants treated with Si-NPs under severe stress conditions to $18.7 \%$ in well-watered plants with no foliar application. The 2E-Tridecen-1-al was changed under different treatments of irrigation regimes and $\mathrm{Si}$ in a range of $7.32-10.50 \%$. Dodecanal (7.2-10.6\%) was different under these treatments in which its highest amount was obtained under moderate water stress and Si-NPs application. The maximum n-Nonane amount (8.7\%) was obtained in well-watered plants.

Table 2

Essential oil composition of coriander under silicon and drought stress in 2019

\begin{tabular}{|c|c|c|c|c|c|c|c|c|c|c|}
\hline \multirow[t]{2}{*}{ Compound } & \multirow[t]{2}{*}{ RI } & \multicolumn{3}{|c|}{ Non-stressed condition } & \multicolumn{3}{|c|}{ Moderate stress } & \multicolumn{3}{|c|}{ Severe stress } \\
\hline & & Control & Si & SiNPs & Control & Si & SiNPs & Control & Si & SiNPs \\
\hline n-Nonane & 900 & 8.70 & 6.70 & 7.60 & 4.60 & 7.80 & 7.30 & 8.50 & 4.30 & 5.70 \\
\hline a-Pinene & 933 & 0.17 & 0.24 & 0.23 & 0.18 & 0.16 & 1.20 & 0.37 & 0.39 & 0.46 \\
\hline n-Decane & 996 & 0.65 & 0.45 & 0.46 & 0.87 & 0.65 & 0.54 & 0.40 & 0.34 & 0.45 \\
\hline n-Octanal & 1005 & 0.56 & 0.43 & 0.56 & 0.32 & 0.12 & 0.00 & 0.45 & 0.56 & 0.00 \\
\hline p-Cymene & 1027 & 0.23 & 0.17 & 0.19 & 0.23 & 0.25 & 0.27 & 0.01 & 0.66 & 0.00 \\
\hline Limonene & 1030 & 0.00 & 0.00 & 0.12 & 0.15 & 0.18 & 0.56 & 0.76 & 0.34 & 0.24 \\
\hline n-Undecane & 1096 & 0.13 & 0.00 & 0.14 & 0.45 & 0.03 & 0.00 & 0.43 & 0.13 & 0.13 \\
\hline Linalool & 1102 & 0.00 & 0.12 & 0.13 & 0.65 & 1.30 & 0.00 & 0.23 & 0.87 & 0.01 \\
\hline n-Nonanal & 1107 & 1.23 & 1.60 & 1.15 & 1.34 & 1.26 & 1.23 & 1.18 & 1.43 & 1.25 \\
\hline n-Decanal & 1219 & 22.50 & 25.50 & 27.60 & 23.50 & 24.45 & 25.40 & 21.20 & 20.80 & 22.30 \\
\hline 2E-Decanal & 1273 & 14.70 & 16.70 & 13.30 & 13.80 & 14.20 & 13.50 & 16.40 & 13.40 & 16.20 \\
\hline 1-Decanol & 1277 & 0.34 & 0.32 & 2.30 & 0.45 & 0.57 & 0.32 & 2.30 & 0.43 & 0.35 \\
\hline Undecanal & 1311 & 3.12 & 2.70 & 3.29 & 3.40 & 3.29 & 3.20 & 3.60 & 3.70 & 2.70 \\
\hline 2E-Undecanal & 1370 & 3.60 & 4.30 & 3.40 & 3.50 & 3.20 & 2.70 & 1.60 & 5.40 & 3.70 \\
\hline Dodecanal & 1413 & 8.70 & 8.70 & 9.70 & 7.60 & 8.70 & 10.60 & 8.80 & 10.20 & 9.90 \\
\hline 2E-Dodecanal & 1467 & 17.80 & 16.70 & 14.50 & 18.70 & 16.70 & 14.50 & 17.80 & 15.60 & 13.90 \\
\hline Tridecanal & 1511 & 0.45 & 0.34 & 0.56 & 0.76 & 0.45 & 0.54 & 0.34 & 0.95 & 0.76 \\
\hline 2E-Tridecen-1-al & 1527 & 1.05 & 1.04 & 0.00 & 1.02 & 1.12 & 0.00 & 1.50 & 1.70 & 1.40 \\
\hline Tetradecanal & 1614 & 1.16 & 1.02 & 0.12 & 1.27 & 1.28 & 1.87 & 1.22 & 1.45 & 1.28 \\
\hline 2E-Tridecen-1-al & 1680 & 10.32 & 8.70 & 9.50 & 9.10 & 7.32 & 7.80 & 8.20 & 9.70 & 9.90 \\
\hline Neocnidilide & 1793 & 2.78 & 2.45 & 1.78 & 3.12 & 2.67 & 3.16 & 2.56 & 2.76 & 4.01 \\
\hline Hexahydrofarnesyl & 1780 & 1.23 & 1.43 & 2.34 & 1.23 & 1.43 & 3.50 & 1.20 & 0.98 & 3.44 \\
\hline Total & & 99.42 & 99.61 & 98.97 & 96.24 & 97.13 & 98.19 & 99.05 & 96.09 & 98.08 \\
\hline
\end{tabular}


Table 3

Essential oil composition of coriander under silicon and drought stress in 2020

\begin{tabular}{|c|c|c|c|c|c|c|c|c|c|c|}
\hline \multirow[t]{2}{*}{ Compound } & \multirow[b]{2}{*}{$\mathbf{R I}$} & \multicolumn{3}{|c|}{ Non-stressed condition } & \multicolumn{2}{|c|}{ Moderate stress } & \multicolumn{4}{|c|}{ Severe stress } \\
\hline & & Control & Si & SiNPs & Control & Si & SiNPs & Control & Si & SiNPs \\
\hline n-Nonane & 900 & 8.30 & 7.90 & 7.60 & 5.70 & 7.10 & 5.90 & 8.30 & 5.20 & 4.90 \\
\hline a-Pinene & 933 & 0.18 & 0.26 & 0.26 & 0.22 & 0.27 & 0.98 & 0.40 & 0.43 & 0.33 \\
\hline n-Decane & 996 & 0.67 & 0.65 & 0.68 & 0.65 & 0.56 & 0.76 & 0.28 & 0.67 & 0.67 \\
\hline n-Octanal & 1005 & 0.53 & 0.34 & 0.47 & 0.65 & 0.87 & 0.90 & 0.12 & 0.00 & 0.54 \\
\hline p-Cymene & 1027 & 0.00 & 0.12 & 0.12 & 0.60 & 0.00 & 0.00 & 0.23 & 0.76 & 0.12 \\
\hline Limonene & 1030 & 0.56 & 0.00 & 0.14 & 0.13 & 0.18 & 0.56 & 0.72 & 0.34 & 0.27 \\
\hline n-Undecane & 1096 & 0.00 & 0.00 & 0.13 & 0.12 & 0.16 & 0.00 & 0.45 & 0.16 & 0.98 \\
\hline Linalool & 1102 & 0.01 & 0.30 & 0.13 & 0.12 & 1.30 & 0.00 & 0.23 & 0.65 & 0.76 \\
\hline n-Nonanal & 1107 & 1.26 & 1.25 & 1.34 & 1.37 & 1.02 & 0.00 & 1.23 & 1.86 & 0.98 \\
\hline n-Decanal & 1219 & 22.90 & 23.40 & 26.70 & 22.40 & 24.30 & 25.20 & 22.10 & 20.81 & 22.70 \\
\hline 2E-Decanal & 1273 & 14.30 & 16.30 & 13.30 & 15.70 & 14.20 & 14.20 & 15.60 & 14.20 & 15.50 \\
\hline 1-Decanol & 1277 & 0.56 & 0.43 & 1.24 & 0.54 & 0.34 & 0.27 & 0.87 & 0.45 & 0.76 \\
\hline Undecanal & 1311 & 3.20 & 2.70 & 3.29 & 3.50 & 3.29 & 3.10 & 3.60 & 3.70 & 1.87 \\
\hline 2E-Undecanal & 1370 & 3.50 & 4.30 & 3.60 & 3.20 & 3.80 & 4.30 & 3.20 & 3.90 & 3.80 \\
\hline Dodecanal & 1413 & 7.23 & 8.23 & 7.89 & 7.30 & 8.70 & 9.20 & 7.60 & 8.30 & 7.80 \\
\hline 2E-Dodecanal & 1467 & 16.80 & 15.60 & 15.60 & 18.71 & 17.60 & 15.60 & 18.20 & 17.50 & 15.60 \\
\hline Tridecanal & 1511 & 0.54 & 0.57 & 0.23 & 0.87 & 0.23 & 0.54 & 0.23 & 0.87 & 0.59 \\
\hline 2E-Tridecen-1-al & 1527 & 0.00 & 1.03 & 1.30 & 1.80 & 0.00 & 1.04 & 1.20 & 1.05 & 1.12 \\
\hline Tetradecanal & 1614 & 1.78 & 1.12 & 1.28 & 1.13 & 1.28 & 1.40 & 1.67 & 1.23 & 1.35 \\
\hline 2E-Tridecen-1-al & 1680 & 10.32 & 9.70 & 9.50 & 9.10 & 7.32 & 7.80 & 8.50 & 9.70 & 10.50 \\
\hline Neocnidilide & 1793 & 2.13 & 0.98 & 1.23 & 1.25 & 2.12 & 1.60 & 2.13 & 3.20 & 1.78 \\
\hline Hexahydrofarnesyl & 1780 & 1.45 & 1.02 & 2.54 & 1.02 & 1.43 & 3.21 & 2.45 & 1.12 & 3.76 \\
\hline Total & & 96.22 & 96.20 & 98.57 & 96.08 & 96.06 & 96.56 & 99.31 & 96.10 & 96.68 \\
\hline
\end{tabular}

The main EO constitutes were n-Decanal, 2E-Dodecanal, 2E-Decanal, 2E-Tridecen-1-al, and n-Nonane, which were obtained to be comparable to previous studies with little differences. Pirbalouti et al. [44] showed the main EO profile of coriander leaves were decanal (0-37.5\%), cis-phytol (1.0-34.1\%), 1-tetradecanol, 2E-dodecenal (8.3-17.2\%), dodecanal (0.5-14.8\%), n-decanol (0.514.8\%), trans-2-undecen-1-ol (trace - 12.9\%), 2E-decenal (0-11.3\%), 1-eicosanol (0-6.4\%), and methyl chavicol (0-6.0\%). Neffati and Marzouk [45] identified 2E-decenal as a main EO compound of Tunisian coriander, followed by decanal, dodecanal, and 2ETridecen-1-al. EO profile can be specified by the presence and amount of the compositions, which may be affected by environmental variations [44]. Plants accumulate the secondary metabolisms when exposed to different stresses through changing their cellular metabolism cope with different challenges [3]. Biosynthesis of secondary metabolites is strongly affected by environmental parameters and genetic factors. Environmental challenges such as stresses can influence major compounds of the EOs [41].

\subsection{Heat map analysis (HMA)}


Figure 5 showed HMA of physiological and biochemical attributes of coriander. The HMA showed severe drought stress was classified in a separated cluster, while well-watered and moderate stress treatments were placed in a distinguished cluster. In Addition, Si and Si-NPs were in a distinguished cluster, while control was classified in another cluster. In both drought and Si classifications, TPC and EO yield were the remarkable variables in distinguishing the clusters; i.e. they covered the wide range of colors, representing their main effect on distinguishing the clusters. According to HMA, TFC and EO yield were the main traits representing the highest variation under stress conditions and Si or Si-NPs foliar application. Therefore, we can remark these variables as the main factor in investigating the response of coriander to these treatments. The main EO compositions were monoterpenes. HMA showed that severe stress significantly differed from well-watered and moderate drought stress. Moreover, both Si and Si-NPs were distinguished from control treatment with respect to the physiological and biochemical attributes of coriander plants.

\section{Conclusions}

Drought is the main environmental stress with the challenge to choose the useful method for mitigating the stress. In the present study, we used Si and Si-NPs to alleviate the adverse effect of drought on growth, physio-chemical attributes, and also essential oil quality and quantity of coriander plants. Moderate drought stress with Si-NPs Si was the best treatment of simultaneous application of drought an Si to reach the highest antioxidant capacity (TPC and TFC) and optimum EO quality and quantity. Severe drought stress was the destructive treatment on growth and yield of coriander. The EO composition showed different behavior to drought and foliar application of Si-NPs. Therefore, coriander plants with high variation in EO profile can be useful to reach the given compound by changing the drought and Si-NPs levels.

\section{Declarations}

\section{Funding}

No funding was received for performing this work.

\section{Author Contribution}

All authors contributed equally to this article.

\section{Conflict of Interest}

The authors declare that they have no conflict of interest.

\section{References}

1. Bukhari MA, Ahmad Z, Ashraf MY, Afzal M, Nawaz F, Nafees M, Manan A (2020) Silicon Mitigates Drought Stress in Wheat (Triticum aestivum L.) Through Improving Photosynthetic Pigments, Biochemical and Yield Characters. Silicon 1-16. https://doi.org/10.1007/s12633-020-00797-4

2. Cheng L, Han M, Yang, LM, Li Y, Sun Z, Zhang T (2018) Changes in the physiological characteristics and baicalin biosynthesis metabolism of Scutellaria baicalensis Georgi under drought stress. Ind Crop Prod 122: 473-482. https://doi.org/10.1016/j.indcrop.2018.06.030

3. Mirzaie M, Ladanmoghadam AR, Hakimi L, Danaee E (2020) Water stress modifies essential oil yield and composition, glandular trichomes and stomatal features of lemongrass (Cymbopogon citratus) inoculated with arbuscular mycorrhizal fungi. J Agr Sci Technol 12: 27-36.

4. Abd El-Mageed TA, Shaaban A, Abd El-Mageed SA, Semida WM, Rady MO (2020) Silicon Defensive Role in Maize (Zea mays L.) against Drought Stress and Metals-Contaminated Irrigation Water. Silicon 1-12. https://doi.org/10.1007/s12633-020- 
5. Fatemi H, Pour BE, Rizwan, M (2020) Foliar application of silicon nanoparticles affected the growth, vitamin C, flavonoid, and antioxidant enzyme activities of coriander (Coriandrum sativum L.) plants grown in lead (Pb)-spiked soil. Environ Sci Pollut Res 1-9. https://doi.org/10.1007/s11356-020-10549-x

6. Ali S, Rizwan M, Noureen S, Anwar S, Ali B, Naveed M, Ahmad P (2019) Combined use of biochar and zinc oxide nanoparticle foliar spray improved the plant growth and decreased the cadmium accumulation in rice (Oryza sativa L.) plant. Environ Sci Pollut Res 26(11): 11288-11299. https://doi.org/10.1007/s11356-019-04554-y

7. Hussain A, Rizwan M, Ali Q, Ali, S (2019) Seed priming with silicon nanoparticles improved the biomass and yield while reduced the oxidative stress and cadmium concentration in wheat grains. Environ Sci Pollut Res 26(8): 7579-7588. https://doi.org/10.1007/s11356-019-04210-5

8. Rastogi A, Tripathi DK, Yadav S, Chauhan DK, Živčák M, Ghorbanpour M, Brestic M (2019) Application of silicon nanoparticles in agriculture. Biotech 9(3): 90-98. https://doi.org/10.1007/s13205-019-1626-7

9. Al-Garni SM, Khan MMA, Bahieldin A (2019) Plant growth-promoting bacteria and silicon fertilizer enhance plant growth and salinity tolerance in Coriandrum sativum. J Plant Interac 14(1): 386-396. https://doi.org/10.1080/17429145.2019.1641635

10. Wei JN, Liu ZH, Zhao YP, Zhao LL, Xue TK, Lan QK (2019) Phytochemical and bioactive profile of Coriandrum sativum L. Food Chem 286: 260-267. https://doi.org/10.1016/j.foodchem.2019.01.171

11. Gastón MS, Cid MP, Vázquez AM, Decarlini MF, Demmel GI, Rossi LI, Salvatierra NA (2016) Sedative effect of central administration of Coriandrum sativum essential oil and its major component linalool in neonatal chicks. Pharm Biol 54(10): 1954-1961. https://doi.org/10.3109/13880209.2015.1137602

12. Sajyan TK, Alturki SM, Sassine, YN (2020) Nano-fertilizers and their impact on vegetables: Contribution of Nano-chelate Super Plus ZFM and Lithovit@-standard to improve salt-tolerance of pepper. Annal Agr Sci. https://doi.org/10.1016/j.aoas.2020.11.001

13. Tripathi DK, Singh S, Singh VP, Prasad SM, Chauhan DK, Dubey, NK (2016) Silicon nanoparticles more efficiently alleviate arsenate toxicity than silicon in maize cultiver and hybrid differing in arsenate tolerance. Front Environ Sci 4: 46-53.

14. Hussain B, Lin Q, Hamid Y, Sanaullah M, Di L, Khan MB, Yang X. (2020) Foliage application of selenium and silicon nanoparticles alleviates $\mathrm{Cd}$ and $\mathrm{Pb}$ toxicity in rice (Oryza sativa L.). Sci Total Environ 712: 136497. https://doi.org/10.1016/j.scitotenv.2020.136497

15. Tripathi DK, Singh S, Singh VP, Prasad SM, Dubey NK, Chauhan DK (2017) Silicon nanoparticles more effectively alleviated UV-B stress than silicon in wheat (Triticum aestivum) seedlings. Plant Physiol Biochemi 110: 70-81. https://doi.org/10.1016/j.plaphy.2016.06.026

16. Mahmoud LM, Dutt M, Shalan AM, El-Kady ME, El-Boray MS, Shabana YM, Grosser, JW (2020) Silicon nanoparticles mitigate oxidative stress of in vitro-derived banana (Musa acuminata 'Grand Nain') under simulated water deficit or salinity stress. South Afric J Bot 132: 155-163. https://doi.org/10.1016/j.sajb.2020.04.027

17. Saki A, Mozafari H, AsI KK, Sani B, Mirza M (2019) Plant yield, antioxidant capacity and essential oil quality of Satureja mutica supplied with cattle manure and wheat straw in different plant densities. Commun Soil Sci Plant Anal 50(21): 2683-2693. https://doi.org/10.1080/00103624.2019.1670835

18. Dhopte AM, Manuel LM (2002) Principles and Techniques for Plant Scientists, 1st end. Updesh Purohit for Agrobios (India), Odhpur, ISBN, 81: 373.

19. Jayaraman J, ayaraman J (1981) Laboratory manual in biochemistry (pp. 271-272). Delhi: Wiley Eastern.

20. Xu BJ, Chang SKC (2007) A comparative study on phenolic profiles and antioxidant activities of legumes as affected by extraction solvents. J Food Sci 72(2): S159-S166. https://doi.org/10.1111/j.1750-3841.2006.00260.x.

21. Zhishen J, Mengcheng T, Jianming W (1999) The determination of flavonoid contents in mulberry and their scavenging effects on superoxide radicals. Food Chem 64(4): 555-559. https://doi.org/10.1016/S0308-8146(98)00102-2

22. European Pharmacopoeia (Vol. 1) (1983). Maissoneuve, SA: Sainte Ruffine. 
23. Adams RP (2007) Identification of essential oil components by gas chromatography/mass spectrometry (Vol. 456). Carol Stream, IL: Allured publishing corporation.

24. Sarker U, Oba S (2018) Drought stress effects on growth, ROS markers, compatible solutes, phenolics, flavonoids, and antioxidant activity in Amaranthus tricolor. Appl Biochem Biotechnol 186(4): 999-1016.

25. Achten WM, Maes WH, Reubens B, Mathijs E, Singh VP, Verchot L, Muys B (2010) Biomass production and allocation in Jatropha curcas L. seedlings under different levels of drought stress. Biomass Bioenergy 34(5): 667-676. https://doi.org/10.1007/s12010-018-2784-5

26. Asgari F, Majd A, Jonoubi P, Najafi F (2018) Effects of silicon nanoparticles on molecular, chemical, structural and ultrastructural characteristics of oat (Avena sativa L.). Plant Physiol Biochem 127: 152-160. https://doi.org/10.1016/j.plaphy.2018.03.021

27. Chen R, Zhang C, Zhao Y, Huang Y, Liu Z (2018) Foliar application with nano-silicon reduced cadmium accumulation in grains by inhibiting cadmium translocation in rice plants. Environ Sci Pollut Res 25(3): 2361-2368. https://doi.org/10.1007/s11356017-0681-z

28. Dien DC, Mochizuki T, Yamakawa T (2019) Effect of various drought stresses and subsequent recovery on proline, total soluble sugar and starch metabolisms in Rice (Oryza sativa L.) varieties. Plant Prod Sci 22(4): 530-545. https://doi.org/10.1080/1343943X.2019.1647787

29. Salehi A, Tasdighi H, Gholamhoseini M (2016) Evaluation of proline, chlorophyll, soluble sugar content and uptake of nutrients in the German chamomile (Matricaria chamomilla L.) under drought stress and organic fertilizer treatments. Asian Pac J Trop Biomed. 6(10): 886-891. https://doi.org/10.1016/j.apjtb.2016.08.009

30. Bayat H, Moghadam AN (2019) Drought effects on growth, water status, proline content and antioxidant system in three Salvia nemorosa L. cultivars. Acta Physiol Plant 41(9): 149. https://doi.org/10.1007/s11738-019-2942-6

31. Gharibi S, Tabatabaei BES, Saeidi G, Goli SAH (2016) Effect of drought stress on total phenolic, lipid peroxidation, and antioxidant activity of Achillea species. Appl Biochem Biotechnol 178(4): 796-809. https://doi.org/10.1007/s12010-015-19093

32. Krol A, Amarowicz R, Weidner S (2014) Changes in the composition of phenolic compounds and antioxidant properties of grapevine roots and leaves (Vitis vinifera L.) under continuous of long-term drought stress. Acta Physiology Plan, 36, 14911499. 10.1007/s11738-014-1526-8

33. Jaafar HZ, Ibrahim MH, Karimi E (2012) Phenolics and flavonoids compounds, phenylanine ammonia lyase and antioxidant activity responses to elevated CO2 in Labisia pumila (Myrisinaceae). Molecul 17(6): 6331-6347.

https://doi.org/10.3390/molecules17066331

34. Hassanvand F, Nejad AR, Fanourakis D (2019) Morphological and physiological components mediating the silicon-induced enhancement of geranium essential oil yield under saline conditions. Ind Crop Prod 134: 19-25. https://doi.org/10.1016/j.indcrop.2019.03.049

35. García-Caparrós P, Romero MJ, Llanderal A, Cermeño P, Lao MT, Segura ML (2019) Effects of drought stress on biomass, essential oil content, nutritional parameters, and costs of production in six Lamiaceae species. Water 11(3): 573-580. https://doi.org/10.3390/w11030573

36. Farouk S, Elhindi KM, Alotaibi MA (2020) Silicon supplementation mitigates salinity stress on Ocimum basilicum L. via improving water balance, ion homeostasis, and antioxidant defense system. Ecotoxicol Environ Saf 206: 111396. https://doi.org/10.1016/j.ecoenv.2020.111396

37. Bahreininejad B, Razmjou J, Mirza M (2013) Influence of water stress on morpho-physiological and phytochemical traits in Thymus daenensis. Int J Plant Prod 234: 151-155.

38. Mohasseli V, Sadeghi S (2019) Exogenously applied sodium nitroprusside improves physiological attributes and essential oil yield of two drought susceptible and resistant specie of Thymus under reduced irrigation. Ind Crop Prod 130: 130-136. https://doi.org/10.1016/j.indcrop.2018.12.058

39. Dianat M, Saharkhiz MJ, Tavassolian I (2016) Salicylic acid mitigates drought stress in Lippia citriodora L.: Effects on biochemical traits and essential oil yield. Biocatal Agr Biotechnol 8, 286-293. https://doi.org/10.1016/j.bcab.2016.10.010

Page 11/14 
40. Farouk S, Omar MM (2020). Sweet basil growth, physiological and ultrastructural modification, and oxidative defense system under water deficit and silicon forms treatment. J Plant Growth Regul 39(3): 1307-1331. https://doi.org/10.1007/s00344-02010071-x

41. Talebi M, Moghaddam M, Pirbalouti AG (2018) Methyl jasmonate effects on volatile oil compounds and antioxidant activity of leaf extract of two basil cultivars under salinity stress. Acta Physiolo Plant 40(2): 34-40. https://doi.org/10.1007/s11738-0182611-1

42. Helaly MN, Farouk S, Arafa SA, Amhimmid NB (2018) Inducing salinity tolerance of rosemary (Rosmarinus officinalis L.) plants by chitosan or zeolite application. Asian J Adv Agr Res 1-20. https://doi.org/10.9734/AJAAR/2018/40051

43. Yaghubi K, Vafaee Y, Ghaderi, N, Javadi T (2019) Potassium silicate improves salinity resistant and affects fruit quality in two strawberry cultivars grown under salt stress. Commun Soil Sci Plant Anal 50(12): 1439-1451. https://doi.org/10.1080/00103624.2019.1621333

44. Pirbalouti AG, Salehi S, Craker L (2017) Effect of drying methods on qualitative and quantitative properties of essential oil from the aerial parts of coriander. J Appl Res Med Arom Plant 4: 35-40. https://doi.org/10.1016/j.jarmap.2016.07.006

45. Neffati M, Marzouk B (2008) Changes in essential oil and fatty acid composition in coriander (Coriandrum sativum L.) leaves under saline conditions. Ind Crop Prod 28(2): 137-142. https://doi.org/10.1016/j.indcrop.2008.02.005

\section{Figures}

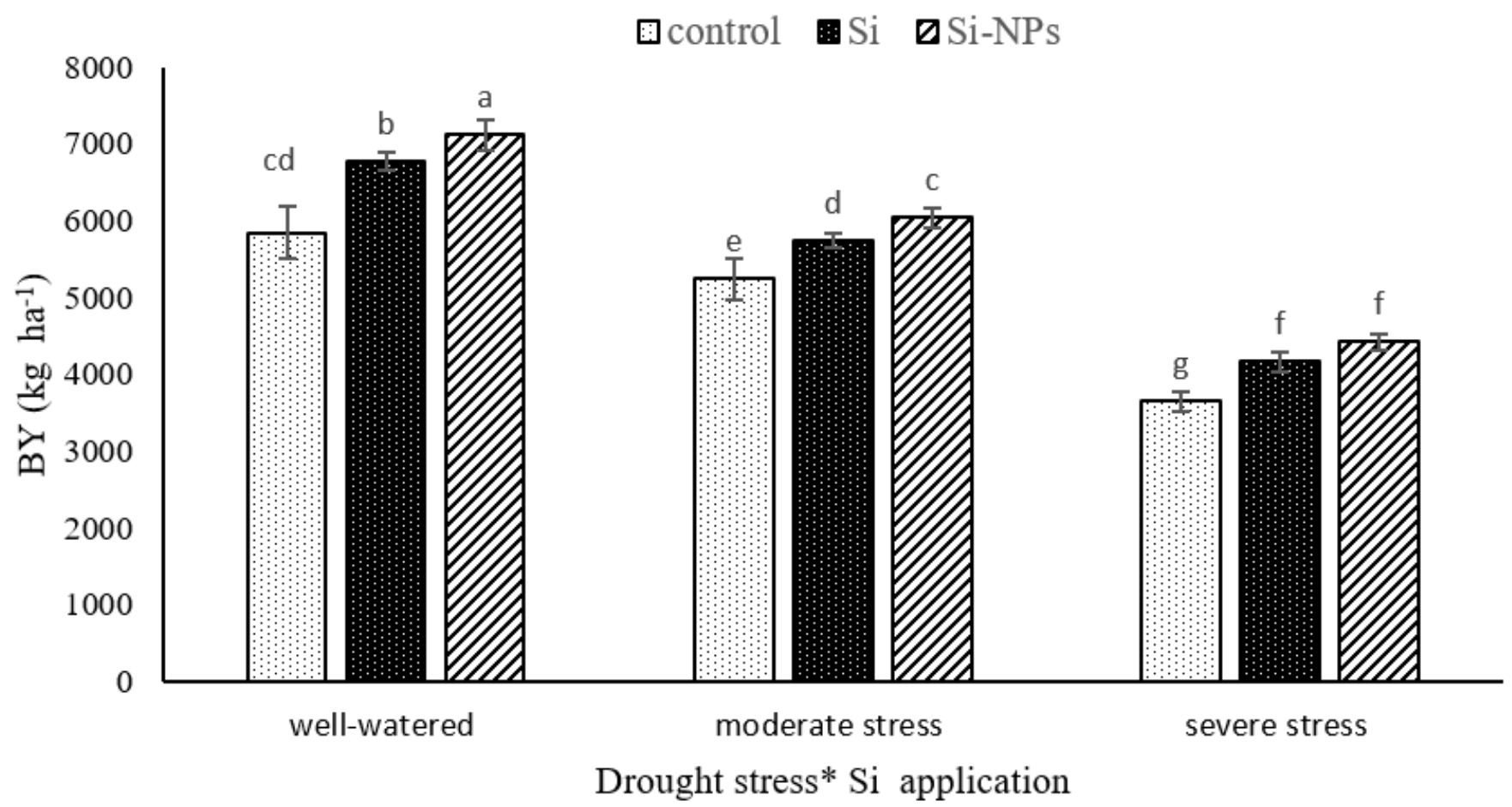

Figure 1

Biological yield (BY) of coriander under drought and silicon application. Values are means \pm standard deviation (SD) of three replications $(n=3)$. Different letters show statistically significant differences among treatments at $P \leq 0.05$. 
a

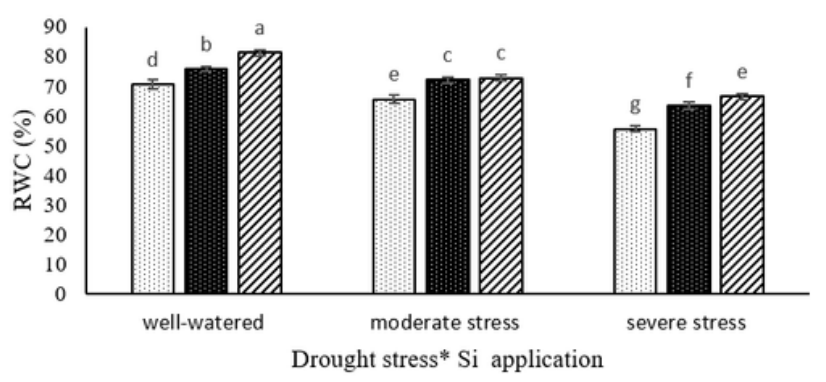

b

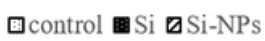

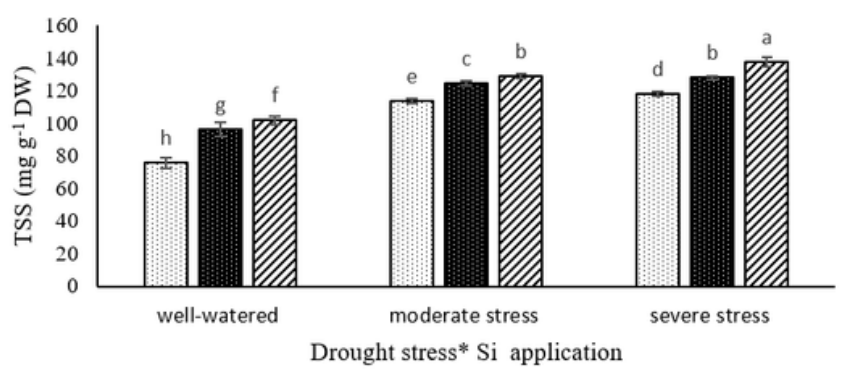

Figure 2

Relative water content (RWC) and total soluble sugar (TSS) of coriander under drought and silicon application. Values are means \pm standard deviation (SD) of three replications $(n=3)$. Different letters show statistically significant differences among treatments at $\mathrm{P} \leq 0.05$.
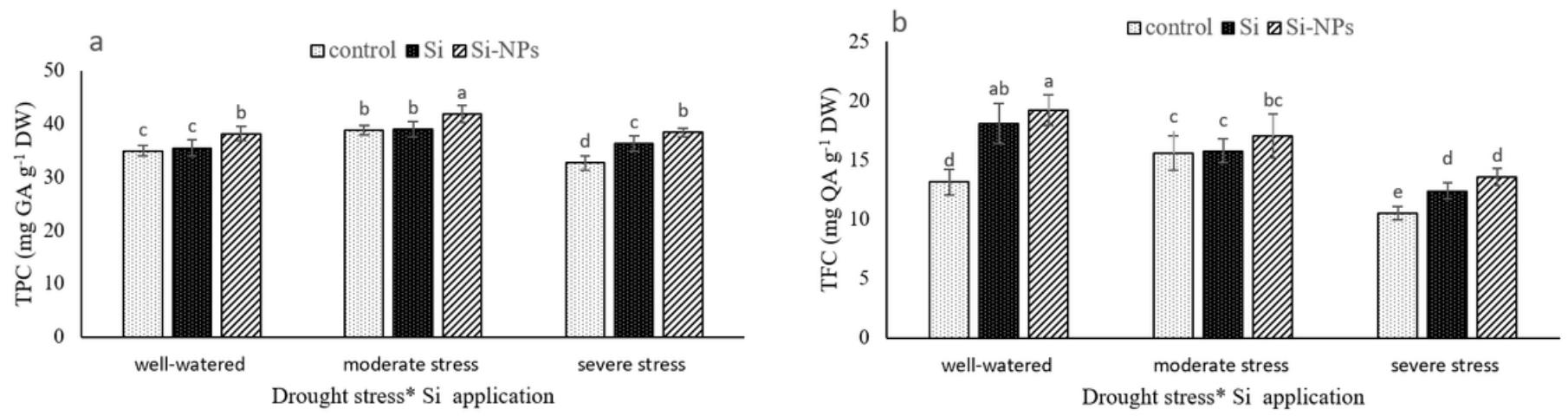

\section{Figure 3}

Total phenolic content (TPC) and total flavonoid content (TFC) of coriander under drought and silicon application. Values are means \pm standard deviation (SD) of three replications $(n=3)$. Different letters show statistically significant differences among treatments at $\mathrm{P} \leq 0.05$.
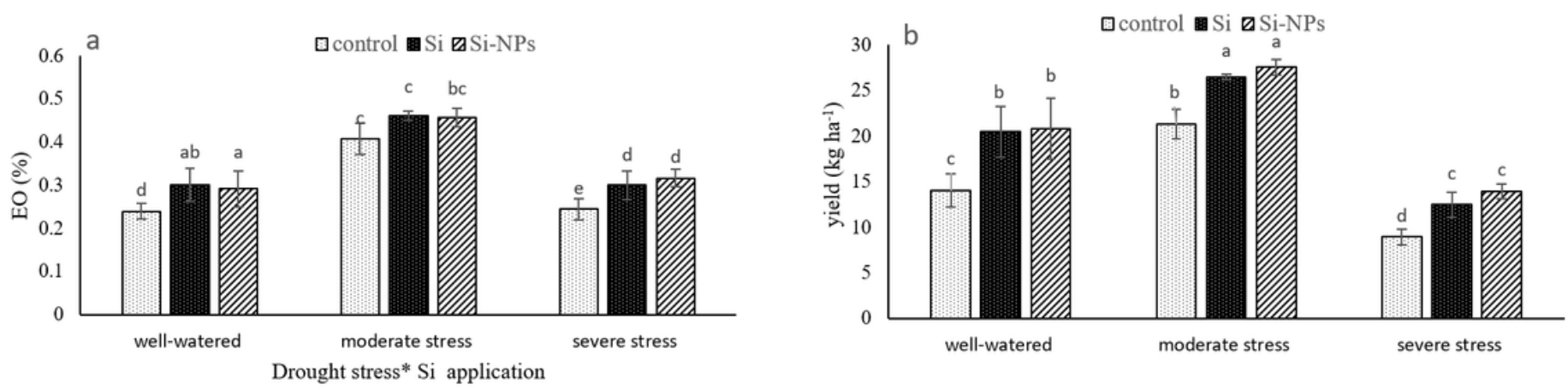

\section{Figure 4}

Essential oil (EO) percentage and yield of coriander under drought and silicon application. Values are means \pm standard deviation $(S D)$ of three replications $(n=3)$. Different letters show statistically significant differences among treatments at $P \leq 0.05$. 

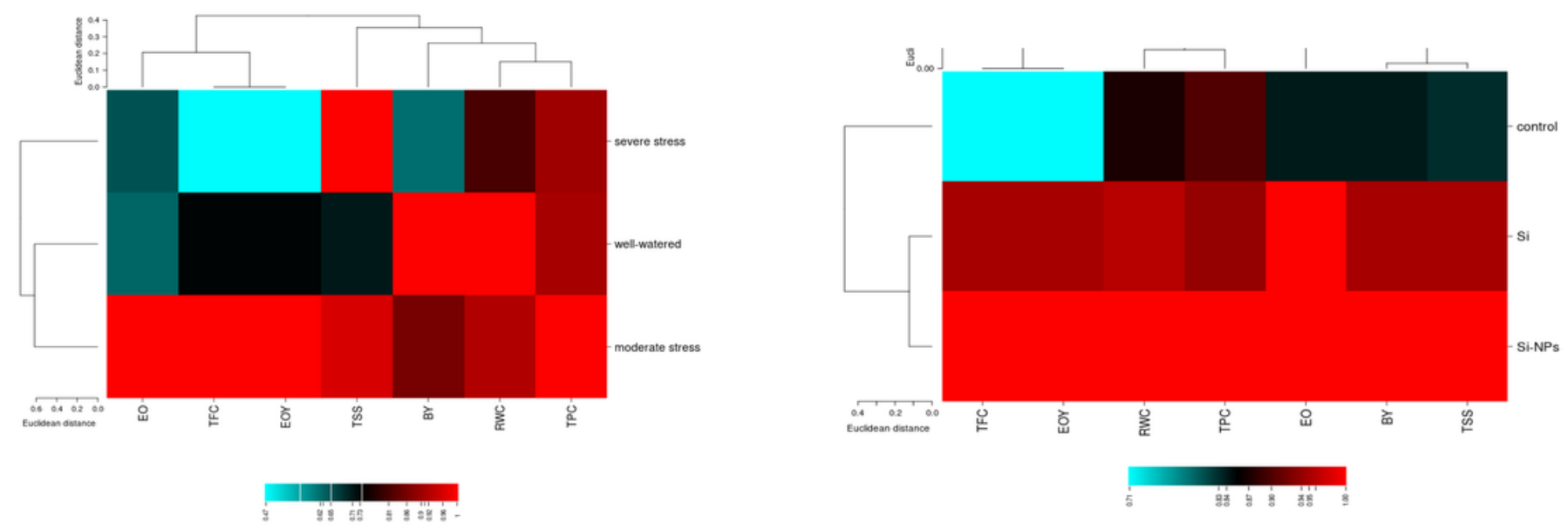

Figure 5

Heat map analysis (HMA) of the studied traits of coriander under drought and silicon 